\title{
Acoustic thermometry in the Arctic Ocean
}

\author{
Peter N. Mikhalevsky \& Alexander N. Gavrilov
}

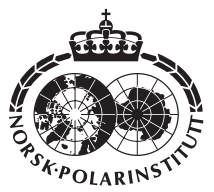

Large increases in the temperature of the Atlantic Layer in the Arctic Ocean have been observed since the early to mid-1990s and have continued through to the present. These changes were detected in 1994 and in 1999 with acoustic "sections" using acoustic thermometry. Both icebreaker and submarine CTD sections have confirmed these observations. Calculations of the travel time of acoustic mode 2 for the submarine CTD sections show a linear correlation with the mean temperature of the Atlantic Layer of the section. A cabled-to-shore undersea mooring system of Arctic Ocean observatories is needed to provide real-time year-round observations using conventional as well as acoustic remote sensing techniques.

P. N. Mikhalevsky, Science Applications International Corporation, 1710 SAIC Dr., McLean, VA 22102, USA; A. N. Gavrilov, P. P. Shirshov Institute of Oceanology, Russian Academy of Science, 36 Nakhimovskii prospekt, Moscow 117851, Russia.

The Arctic Ocean plays a key role in the global thermohaline circulation of the world's oceans and exercises considerable influence on global climate, especially in the Northern Hemisphere. Climate models predict that the Arctic regions should be the first to experience the influence of global warming (Manabe et al. 1992). This influence is possibly already happening at present in the form of considerable warming of water in certain regions of the Arctic Ocean. Since the early 1990s inflow of warmer water from the Northern Atlantic into the Arctic Basin has resulted in a temperature increase in the Atlantic Layer from approximately $50 \mathrm{~m}$ to $1000 \mathrm{~m}$ in the regions along the Atlantic water circulation (Carmack et al. 1995).

The Arctic Ocean is the least accessible for oceanographic measurements with the use of traditional "contact" methods from research vessels due to severe climatic conditions and the yearround sea ice cover. Arctic researchers therefore need remote sensing methods to make year-round observations. However, methods of remote observation of the ocean such as satellite altimetry of the ocean surface and measurements of sea surface temperature are not possible in the Arctic because of the perennial ice cover. Autonomous vehicles and sub-surface drifters are still under development. Low frequency acoustics offers an effective technique for remote sensing of the water temperature in the Arctic Ocean. With receiving hydrophone arrays that are cabled to shore, ocean temperature measurements can be provided in real time.

Acoustic thermometry is a proven technical approach to the problem of remote observation of large-scale variation of temperature in the ocean, including climatic changes (Dushaw et al. 2001). The method of acoustic thermometry of the ocean suggested by Munk \& Forbes (1989) is based upon the almost linear dependence of the sound speed in water on temperature. Measuring the travel time of acoustic propagation between a fixed source and a receiver in the ocean, it is possible to determine changes in the average temperature of water along the propagation path. Sound can propagate in the ocean over thousands of kilometres, which makes it possible to create integral acoustic thermometers overlapping in individual large basins, and with tomographic inversion these integral measurements can provide spatial resolution directly proportional to the number and density of intersecting acoustic paths in each of the basins. 


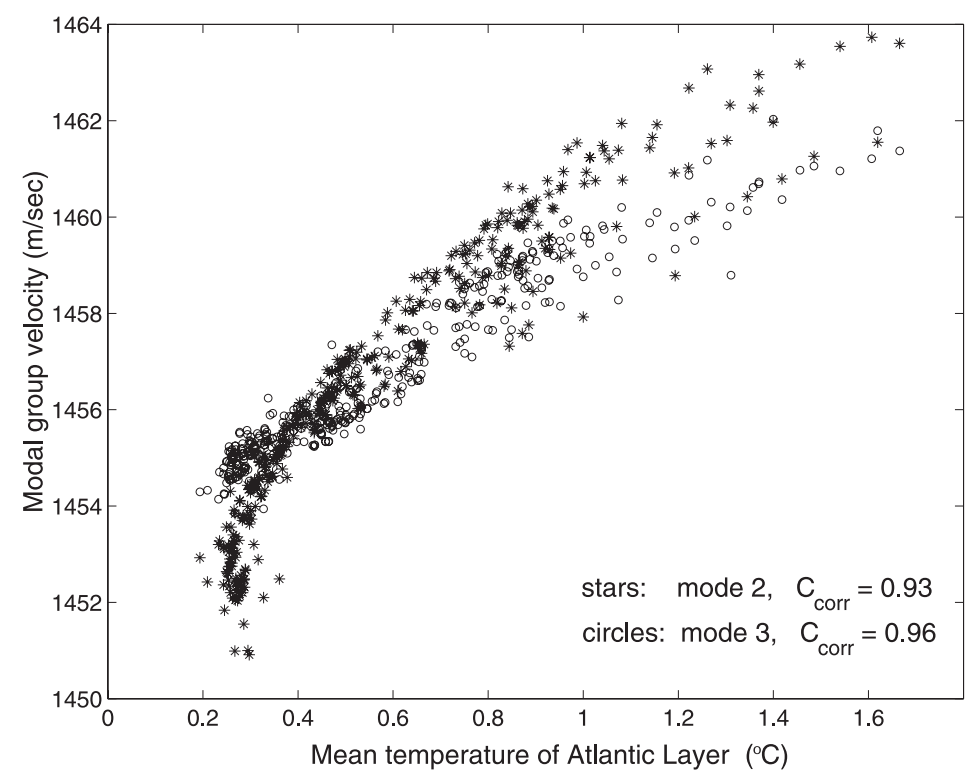

Fig. 1. The mean temperature between the zero degree isotherms of 754 CTD profiles from the Arctic Ocean plotted against the modal group velocity for that profile for mode 2 (stars) and mode 3 (circles). $\mathrm{C}_{\text {corr }}$ is the correlation coefficient calculated for the best linear fit.

\section{Acoustic propagation in the Arctic Ocean}

The efficiency of acoustic thermometry in the Arctic Ocean follows from the unique characteristics of sound propagation in the Arctic underwater acoustic channel. The acoustic energy of low frequency signals propagates in stable welldefined waveguide modes in the vertically stratified water mass layers of the Arctic Ocean. When propagating, the lowest modes (mode 1 at 20 $\mathrm{Hz}$, for example) occupy mainly the upper mixed layer of cold and less saline Arctic waters. The maximum energy of the higher modes (modes 2 and 3 at $20 \mathrm{~Hz}$ ) propagates in the intermediate layer of warmer and more saline waters of Atlantic origin (hence the name Atlantic Layer) that circulate over the entire Arctic Basin (Mikhalevsky et al. 1995). There is therefore an opportunity for remote observation of the temperature variation in the typical water mass layers of the Arctic Ocean by filtering the signals arriving in different acoustic modes. The modes travel at different group velocities corresponding to the different sound speeds in the Arctic water layers so simple time filtering can be done for those paths whose ranges are long enough for the modes to separate, typically greater than several hundred kilometres. For shorter ranges the modes can be filtered spatially with a vertical array.
Figure 1 shows the relationship between the average temperature of the Atlantic Layer, defined as a layer bounded by the zero degree isotherms, and the group velocity of modes 2 and 3, i.e. the velocity of propagation of an acoustic pulse signal. 754 CTD profiles measured in the Arctic since the 1950s were used to calculate this correlation. The plot clearly shows that the relationship between the acoustic modal group velocity and the Atlantic Layer temperature is almost linear and the correlation coefficient calculated for the best linear fit is close to unity. Since the actual acoustic thermometry measurement is a travel time along a propagation path the correlation of the travel time with the average temperature in the Atlantic Layer on a specific path effectively depends upon a much smaller subset of the profiles shown in Fig. 1 (which represents the entire Arctic) and should be calculated for the specific path as done below. The correlations are even higher if one considers profiles from only the western Arctic (Makarov and Canada basins) and the eastern Arctic (Nansen and Amundsen basins), which correspond to the points less than $\sim 0.7^{\circ} \mathrm{C}$ and greater than $\sim 0.7^{\circ} \mathrm{C}$, respectively, in Fig. 1.

In April 1994 acoustic transmissions at $20 \mathrm{~Hz}$ were made from the ice camp Turpan north of Svalbard across the entire Arctic Ocean to receive arrays located at ice camp Narwhal in the Lincoln Sea and ice camp SIMI in the Beaufort Sea. This 
Fig. 2. A notional monitoring grid for the Arctic Ocean. The stars represent the three autonomous acoustic sources. The filled and open circles indicate the cabled receive arrays and Arctic Ocean observatories. The open circle in the Lincoln Sea represents an existing sea-shore interface. The open circle in the Beaufort Sea represents a sea-shore interface which does not yet exist. The open circle in the Chukchi Sea shows the APLIS Ice Camp location. The short-dashed grey line from the ACOUS source to the Lincoln Sea is the acoustic path along which acoustic thermometry

transmissions were made from October 1998 to December 1999. The long-dashed grey line is the acoustic path from the ACOUS source to the APLIS Ice Camp in the Chukchi Sea along which acoustic thermometry measurements were made in April 1999.

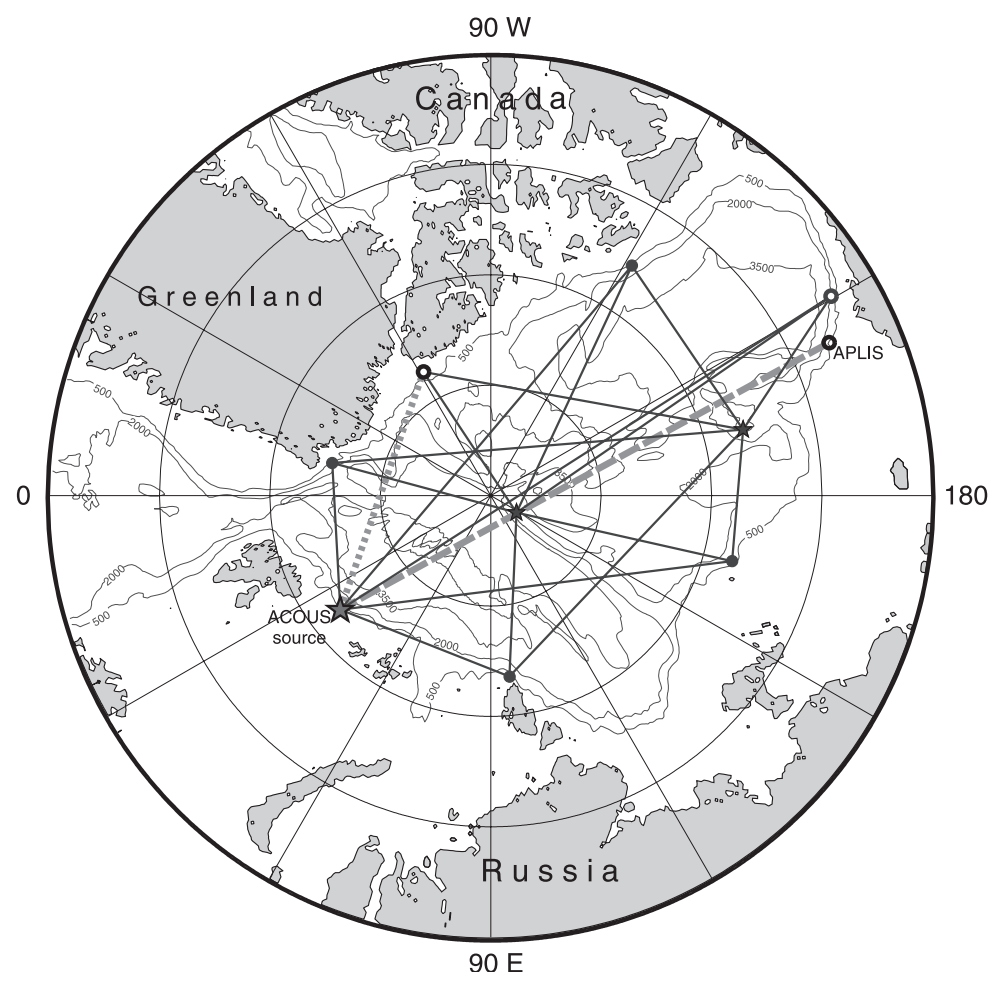

was the Transarctic Acoustic Propagation (TAP) Experiment (Mikhalevsky et al. 1999). The travel time of mode 2 measured in the TAP experiment was shorter by approximately 2 seconds $(2.3 \pm$ $1.2 \mathrm{sec})$ relative to that modelled for the Arctic Ocean climatology data along the propagation path, which indicated a warming of the Atlantic Layer by almost $0.4{ }^{\circ} \mathrm{C}\left( \pm 0.2{ }^{\circ} \mathrm{C}\right)$ of the range averaged maximum temperature in depth. The maximum in depth of the range average of the temperature difference in the Atlantic Layer computed from the US Navy Generalized Digital Environmental Model (GDEM) (Teague et al. 1990; Teague et al. 1987) and US-Russian Environmental Working Group (EWG) Arctic database (EWG 1997) with the 1995 submarine CTD transect showed $0.3{ }^{\circ} \mathrm{C}$ and $0.5{ }^{\circ} \mathrm{C}$ increases, respectively. Error statistics provided with the EWG database indicate an error of $\pm 0.2{ }^{\circ} \mathrm{C}$ for an average over the three major Arctic basins spanned by the transect. The April 1994 TAP acoustic section was the first basin scale measurement indicating a net warming over such a large scale in the Atlantic Layer of the Arctic Ocean. The Arctic Ocean Section of the US ice-breaker
Polar Sea and the Canadian ice-breaker Louis S. St. Laurent conducted in August 1994, as well as subsequent basin transects performed by the US Navy Scientific Ice Expeditions (SCICEX; Lamont-Doherty Earth Observatory 2001), confirmed the results of the acoustic measurements.

The warming of the Atlantic Layer in the 1990s is an established fact. What has not been established is whether this change is a manifestation of a secular global climate change trend with an anthropogenic fingerprint, or a "natural" oscillation (Proshutinsky \& Johnson 1997; Grotefendt et al. 1998). The need for a real-time long-term observational system is clearly evident to understand these phenomena in the Arctic Ocean.

\section{Arctic climate observations using underwater sound}

In October 1998, as part of the joint US-Russian Arctic Climate Observations using Underwater Sound (ACOUS) project, the first acoustic sourcewas deployed by the Russian team in the Franz Victoria Strait. At the same time, a US-Canadian 

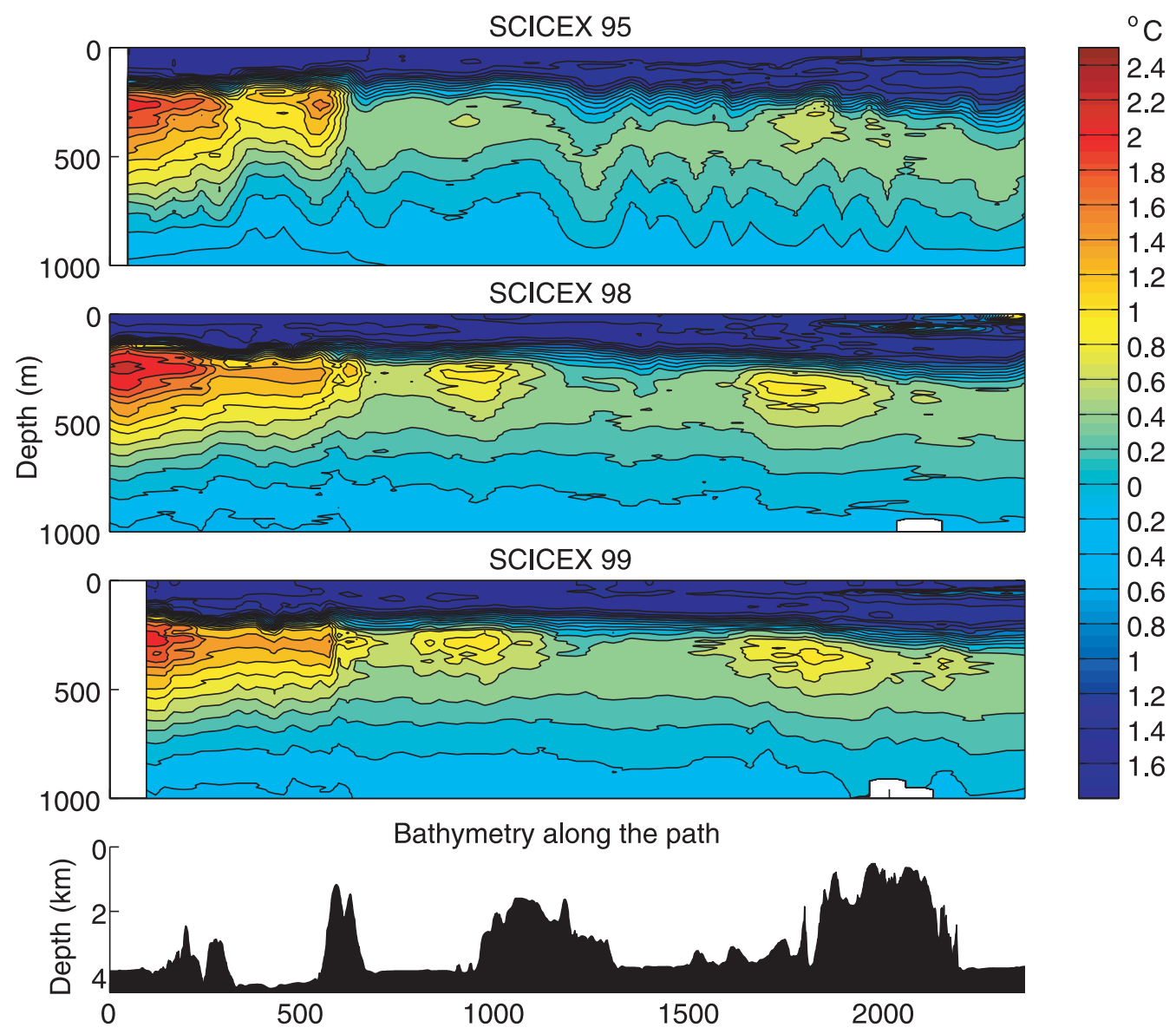

Range $(\mathrm{km})$, from $85.03 \mathrm{~N}, 47.1 \mathrm{E}$ to $73.65 \mathrm{~N}, 155.55 \mathrm{~W}$

Fig. 3. Temperature sections from SCICEX 1995, 1998 and 1999 across the Arctic Basin with the coincident bathymetry. The significant warming in the Atlantic Layer is evident as topographically guided extensions of the Atlantic water circulation. An average in range of these sections plotted as a function of depth shows a $0.4{ }^{\circ} \mathrm{C}$ maximum increase between 1995 and $1998-99$ at approximately $250 \mathrm{~m}$.

team was in the Lincoln Sea deploying an autonomous receive array. In April 2001 this receive array was recovered. This vertical array was moored from the bottom in about $550 \mathrm{~m}$ of water. The array consisted of 8 hydrophones spaced at $70 \mathrm{~m}$ intervals, starting at $12 \mathrm{~m}$ from the bottom. The array also had 5 self-recording micro-CTDs that record temperature and salinity every 10 minutes. There were two self-recording transceivers on the array that interrogated three bottommounted transponders to measure the shape of the array. The source-receiver pair creates a propagation path that crosses the Arctic Basin just north of the Fram Strait (Fig. 2). Preliminary analysis of the data shows that the source operated successfully until 8 December 1999, when it ceased transmissions due most likely to depletion of the batteries.

The source was moored from the bottom at a depth of $60 \mathrm{~m}$ below the sea surface and transmitted a Maximal Length Sequence (MLS) tomographic signal at $20.5 \mathrm{~Hz}$ every four days at 00:00 GMT. The total signal duration is about 20 minutes. The signal level is $250 \mathrm{~W}$ ( $195 \mathrm{~dB}$ re $1 \mu \mathrm{Pa})$ of acoustic power. The transmission time was controlled by a quartz oscillator that was corrected every four days by a rubidium clock, based on a technique that has been in use on 
Fig. 4. (a) Average temperatures between the zero degree isotherms plotted as a function of range for SCICEX 1995, 1998 and 1999. The numbers in the upper right corner are the averages over the range of the plotted curves and therefore represent the twodimensional average temperature of each section. (b) The mode 2 group velocity plotted as a function of range for SCICEX 1995, 1998 and 1999. (b) The total computed travel time for mode 2 is shown in the lower left corner.
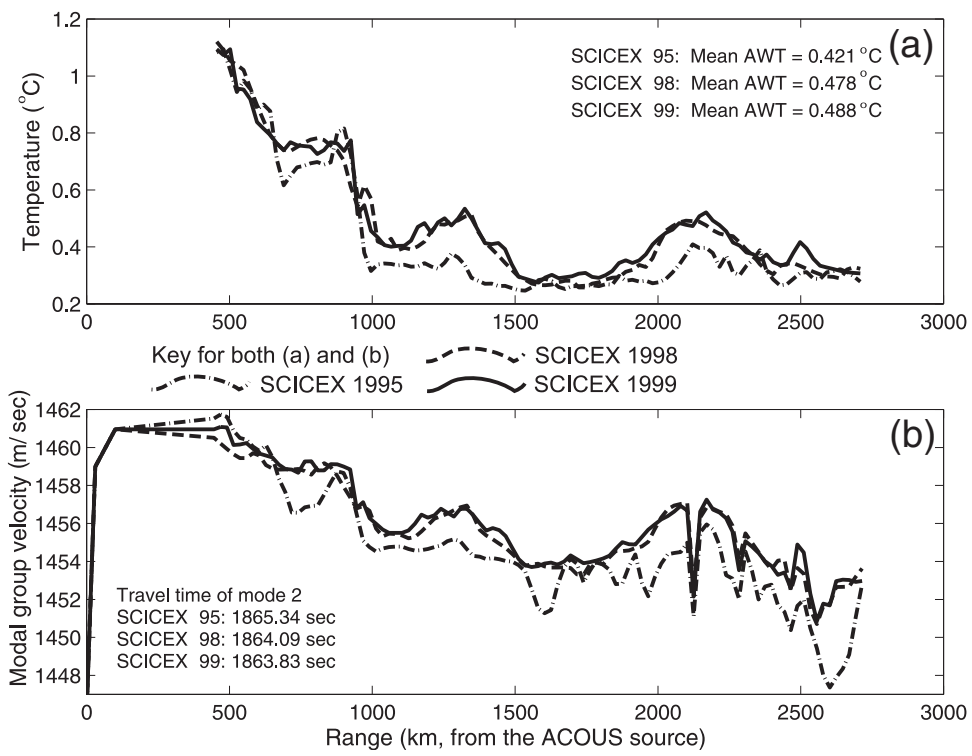

autonomous tomographic moorings for some time (Worcester et al. 1985). The clock was synchronized to GPS just before deployment, and predeployment tests indicated better than $0.6 \mathrm{msec}$ absolute timing accuracy. The acoustic data set from this path should reveal any changes in the net heat influx into the Arctic Ocean over the 14 month period between October 1998 and December 1999. These acoustic data will be compared with new models under development at the University of Alaska Fairbanks, which are attempting to nowcast and forecast the regime shifts and current state of the Arctic Ocean (Johnson et al. 1999).

In April 1999 the ice camp APLIS was established in the Chukchi Sea to support the SCICEX-1999 expedition (Fig. 2). Two recordings of the regular ACOUS transmissions were made at the ice camp on 9 and 13 April. The acoustic path from the ACOUS source to APLIS is close to the SCICEX transects conducted in 1995, 1998 and 1999. Figure 3 shows the temperature field along the path in 1995, 1998 and 1999 constructed from expendable CTDs launched from the submarine at approximately $40 \mathrm{~km}$ intervals. The expendable CTD probes have an accuracy of $\pm 0.035{ }^{\circ} \mathrm{C}$ in temperature and $4.6 \mathrm{~m}$ or $2 \%$ of depth, whichever is greater, and make measurements between $25 \mathrm{~m}$ and $1000 \mathrm{~m}$ in depth. The areas of warmer Atlantic water located to the left of the major undersea ridges in the figure coincide with the main streams of the Atlantic Layer circulation in the Arctic Basin.

The plot clearly shows the considerable warming in the Atlantic Layer in 1998 and 1999 relative to 1995 . The maximum in depth of the range averaged temperature difference between 1995 and 1999 showed a $0.4{ }^{\circ} \mathrm{C}$ increase in temperature, and from 1998 to 1999 a $0.05{ }^{\circ} \mathrm{C}$ increase. However, due to the change in depth of the warm cores of the Atlantic Layer from year to year (Fig. 3), it is estimated that the error of the range averaged maximum is probably close to $\pm 0.05{ }^{\circ} \mathrm{C}$. A more robust and statistically stable measurement, which is not going to be sensitive to depth changes of the warm cores within the Atlantic Layer, is the range and depth averaged temperature for the section between the $0.0{ }^{\circ} \mathrm{C}$ isotherms that define the Atlantic Layer. Given that there are approximately 4000 independent data points from the expendable CTDs in the Atlantic Layer of each section, the error of the average temperature is $\pm 0.6 \mathrm{~m}^{\circ} \mathrm{C}$. The Atlantic Layer in the SCICEX-99 transect was warmer by $0.01 \pm$ $0.0006{ }^{\circ} \mathrm{C}$ on average over the entire section (range and depth) than that in 1998. Figure 4a shows the variation of the mean Atlantic water temperature along the section and the section average values. The calculated group velocity of mode 2 (Fig. 4b) strongly correlates with the horizontal variation of the mean temperature. The travel time of mode 2 modelled for the T/S fields 
in 1995, 1998 and 1999 depends on the total section average of the Atlantic Layer temperature almost linearly (Fig. 5).

The travel time of mode 2 measured at APLIS in April 1999 was $2.7 \pm 1.3$ seconds shorter compared to the April 1994 TAP measurement (corrected for the different path lengths). This implies a $0.5 \pm 0.25{ }^{\circ} \mathrm{C}$ increase in the range averaged maximum temperature in depth over 5 years compared with the submarine measured increase of $0.4 \pm 0.05{ }^{\circ} \mathrm{C}$ from 1995 to 1999 over 4 years discussed above. The measured travel time of mode 2 along the APLIS path was $1.2 \pm 0.5$ seconds shorter than modelled using the SCICEX-99 CTD data. Since SCICEX could not sample the first $300 \mathrm{~km}$ section of the acoustic propagation path (due to operational restrictions), some recent oceanographic measurements from this region in 1993 were used for the acoustic modelling for the first $300 \mathrm{~km}$. This $300 \mathrm{~km}$ section is the warmest part of the acoustic path, because it stretches from the Franz Victoria Strait toward the North Pole and samples the extension of the West Spitsbergen Current. Such a compilation of older oceanographic data with the newer SCICEX data on this section could explain the disagreement between the experimental and modelling results for 1999, with the modelling results biased slower, as was observed. Nevertheless, both the modelling and the experimental acoustic and submarine CTD data demonstrate considerable warming in the Atlantic Layer along this section in 1999 relative to 1994 and 1995.

The errors associated with the absolute travel times reported above for mode 2 from the TAP and APLIS experiments were dominated by the fact that in TAP the source transmission was initiated by manual synchronization with the rubidium clock (the receive systems were electronically synchronized) and in APLIS the receive system had to be manually synchronized with a GPS (a consequence of experiment field problems). This resulted in absolute travel time measurement errors of \pm 1.2 seconds in TAP and \pm 0.5 seconds in APLIS. With electronic synchronization the travel time errors and the accuracy are reduced to the precision of the MLS measurement, which depends upon the bandwidth of the MLS waveform $(1.5 \mathrm{~Hz}$ for TAP and $2 \mathrm{~Hz}$ for APLIS) and the received signal-to-noise ratio (SNR). For TAP and APLIS, the longest trans-Arctic path to the Beaufort and Chukchi seas, respectively, had a received post-processing SNR of $\sim 18 \mathrm{~dB}$ and $\sim 21 \mathrm{~dB}$ for mode 2, respectively. For the shorter path to the Lincoln Sea the SNR was even higher. As shown in Mikhalevsky et al. 1999 (Eq. 1), this yields a time measurement precision of $\sim 30 \mathrm{msec}$ and $\sim 22 \mathrm{msec}$, respectively, by picking the peak of the pulse compressed waveform in time. Travel time changes using a modal phase measurement method (also shown in Mikhalevsky et al. 1999) further reduced these errors to $\sim 0.7 \mathrm{msec}$ and $\sim 0.5 \mathrm{msec}$, respectively. Using the linear trend shown in Fig. 5 of $0.044^{\circ} \mathrm{C} \mathrm{sec}^{-1}$, a $22 \mathrm{msec}$ travel time error would correspond to $0.9 \mathrm{~m}^{\circ} \mathrm{C}$ error in the section average temperature on this path (and $0.02 \mathrm{~m}^{\circ} \mathrm{C}$ error using the phase method).

These small errors are also a consequence of the nearly perfect linear relationship of the section average temperature and travel time for the three data points shown in Fig. 5. If this linear relationship does not hold up when new data are available then these errors must be increased depending upon the goodness of the linear fit.

Finally, the travel time accuracies assume that the modal propagation is adiabatic. If significant mode coupling occurs along the propagation path then associating a measured travel time with a particular mode is problematic. Even a small amount of mode coupling can increase the errors associated with the waveform peak picking measurement discussed above. Analysis of the bathymetrically caused mode coupling on the Lincoln Sea path during the TAP experiment (Pawlowicz et al. 1996; Gavrilov \& Mikhalevsky 2001) has shown that the phase method is much more robust to errors caused by mode coupling than the waveform peak picking method. The analysis also showed that travel time errors using the phase method would be less than $10 \mathrm{msec}$. The measured SCICEX CTD and acoustic data, and acoustic modelling using the SCICEX CTD data, have shown that the warming in the Atlantic Layer of the Arctic Ocean have decreased the trans-Arctic travel time of mode 2 by $\sim 0.4 \mathrm{sec} / \mathrm{yr}$. Clearly, these changes, and changes even two orders of magnitude less than this, on an annual basis will be easily detectable using acoustic thermometry.

\section{A future monitoring network for the Arctic Ocean}

A notional monitoring network for the Arctic Ocean is shown in Fig. 2. This grid provides an integrated Arctic Ocean observing system 
Fig. 5. The computed travel time for mode 2 for the SCICEX 1995, 1998 and 1999 sections plotted against the average temperatures for the sections. Note the almost linear correlation between the travel time for mode 2 and the average Atlantic Layer section temperature for the three years. The error bars shown for the computed travel time (vertical) and for the section average temperature (horizontal) are described in the text.

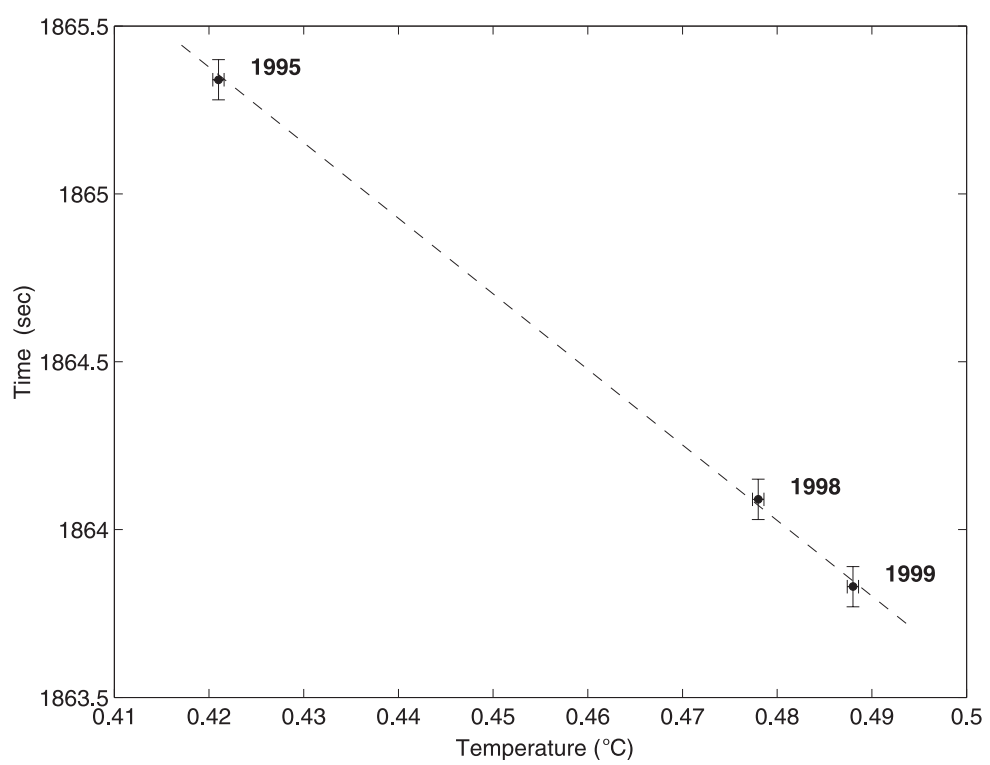

exploiting the capabilities of acoustic remote sensing and direct measurements of important physical ocean properties using cabled moorings and autonomous acoustic sources. The notional network consists of 6 ocean observatories with acoustic receive arrays and 3 autonomous acoustic sources. The scheme shows that an 18 acoustic path system will sample every major Arctic sub-basin and intersect every major branch of the Atlantic and Pacific water circulation. The acoustic signal takes $30 \mathrm{~min}$ to propagate along the longest path from Franz Josef Land to the Beaufort Sea array. The ACOUS source currently operating in the Arctic sends a 20 min signal every four days. Thus, the notional network shown here could provide a snapshot of the entire Arctic Ocean in less than 1 hour every 4 days, and could operate for years with all of the data being provided to researchers in real-time. The data would provide information on temperature changes in the upper mixed layer and the Atlantic Layer, through inversion of the mode arrival times. The inherent low spatial resolution of the acoustic grid could be later improved with the addition of more sources and receivers. However, even the notional grid proposed could alert researchers to important changes anywhere in the entire Arctic Basin for more detailed ice-breaker and ice camp based research. In addition to the acoustic data, the observatories would be equipped with oceanographic, biological, chemical, sea ice and seismic sensors. This cabled network would provide coincident long term Eulerian time series of all these measurements.

Propagation loss of acoustic signals in the Arctic channel strongly depends on the thickness and roughness of the ice cover. This suggests a way to remotely observe variations of the average thickness of sea ice in the Arctic (Gavrilov \& Mikhalevsky 1995). Together with satellite data on ice concentration, such measurements may allow us to obtain direct estimates of the volume of floating sea ice in the Arctic Ocean, which is one of the important climate variables. However, the accuracy of such remote sensing of sea ice thickness needs to be investigated in more detail and with experimental measurements.

The notional network represents approximately $24000 \mathrm{~km}$ of acoustic path length. To obtain by direct measurement of temperature an average temperature on these 18 acoustic paths that would be equivalent to the acoustic thermometry, it would require sampling along each path at the mesoscale correlation length of approximately 50 $\mathrm{km}$. This would therefore require installing and maintaining a continuous presence of $600-1000$ buoys equipped with at least a $1 \mathrm{~km}$ long thermister chain that must be mounted through the ice in locations that span the entire Arctic Basin or performing continuous ice-breaker or submarine transects, neither of which is economically or even physically possible for continuous sam- 
pling even on a seasonal basis. The accuracy of the submarine sampled section temperature average was shown to be approximately $\pm 0.6 \mathrm{~m}^{\circ} \mathrm{C}$ and the acoustic measurement is comparable or better with an accuracy of $\pm 0.9 \mathrm{~m}^{\circ} \mathrm{C}$ or $\pm 0.02 \mathrm{~m}^{\circ} \mathrm{C}$ for the waveform time and phase method respectively. Acoustic thermometry provides a way to measure the average temperature of the Arctic Ocean water masses synoptically and continuously, unavailable by other means.

\section{Conclusions}

The travel time of waveguide modes of a low frequency acoustic signal propagated in the Arctic Ocean is a precise measure of the average temperature in the main typical water layers along the acoustic path.

The two acoustic sections of April 1994 and April 1999 detected basin scale warming in the Atlantic water layer of the Arctic Ocean. These results have been confirmed by the SCICEX expendable CTD transects. Under the ACOUS program a 14 month time series has been collected and is currently being analysed.

New technologies for synoptic, real-time, autonomous and unmanned operation are required if we are going to be able to make observations year-round on the spatial and temporal scales needed to understand the changes that are already occurring in the Arctic Ocean. A network of cabled-to-shore Arctic moorings (3 sources and 6 receivers/observatories) would provide realtime year-round synoptic measurement of the average temperature of the Atlantic Layer and other important variables in the Arctic Ocean.

Acknowledgements.-The work was funded by the National Science Foundation (Office of Polar Programs), the Office of Naval Research (High Latitude Programs), the US Civilian Research and Development Foundation, and the Ministry of Science and Technology of the Russian Federation.

\section{References}

Carmack, E. C., Aagaard, K., Swift, J. G., Macdonald, R. W., McLaughlin, F. A., Perkin, R. G. \& Jones, P. E. 1995: The Arctic is warming: results from the US/Canada 1994 Arctic Ocean Section. In: The abstracts of the XXI General Assembly of IAPSO. Honolulu, HI, August 1995. Pp. 26-27. International Association for the Physical Sciences of the
Oceans.

Dushaw, B., Bold, G., Chiu, C. S., Colosi, J., Cornuelle, B., Desaubies, Y., Dzieciuch, M., Forbes, A., Gaillard, F., Gould, J., Howe, B., Lawrence, M., Lynch, J., Menemenlis, D., Mercer, J., Mikhalevsky, P. N., Munk, W., Nakano, I., Schott, F., Send, U., Spindel, R., Terre, T., Worcester, P. \& Wunsch, C. 2001 Observing the ocean in the 2000s: a strategy for the role of acoustic tomography in ocean climate observation. In N. R. Smith \& C. J. Koblinsky: Observing the ocean in the 21st century. Melbourne, Australia: Global Ocean Data Assimilation Experiment (GODAE) Project Office.

EWG (Environmental Working Group) 1997: Joint U.S.Russian Atlas of the Arctic Ocean (CD-rom). Boulder, CO: National Snow and Ice Data Center.

Gavrilov, A. N. \& Mikhalevsky, P. N. 1995: Modeling an acoustic response to long-term variations of water and ice characteristics in the Arctic Ocean. Proceedings of IEEE Oceans '95. Vol. 1. Pp. 247-253. San Diego, CA: IEEE.

Gavrilov, A. N., \& Mikhalevsky, P. N. 2001: Mode coupling effects in acoustic thermometry of the Arctic Ocean. In M. Taroudakis \& G. Makrakis (eds.): Inverse problems in underwater acoustics. Pp. 105-126. New York: Springer.

Grotefendt, K., Logemann, K., Quadfasel, D. \& Ronski, S. 1998: Is the Arctic Ocean warming? J. Geophys. Res. 103(C12), 27,679-27,687.

Johnson, M., Proshutinsky, A. \& Polyakov, I. 1999: Atmospheric patterns forcing two regimes of Arctic ice-ocean circulation: a return to anticyclonic conditions? Geophys. Res. Lett. 26, 1621-1624.

Lamont-Doherty Earth Observatory 2001: Website for SCICEX (Scientific Ice Expeditions) at http://www. ldgo.columbia.edu/SCICEX/.

Manabe, S., Spelman, M. J. \& Stouffer, R. J. 1992: Transient response of a coupled ocean-atmosphere model to gradual change of atmospheric $\mathrm{CO}_{2}$. J. Clim. 5, 105-126.

Mikhalevsky, P. N., Baggeroer, A. B., Gavrilov, A. N. \& Slavinsky, M. 1995: Experiment tests use of acoustics to monitor temperature and ice in the Arctic Ocean. Eos Trans. 76, 265-269.

Mikhalevsky, P. N., Gavrilov, A. N. \& Baggeroer, A. B. 1999: The Transarctic Acoustic Propagation Experiment and climate monitoring in the Arctic. IEEE J. Ocean. Eng. 24, 183-201.

Munk, W. \& Forbes, A. M. G. 1989: Global ocean warming: an acoustic measure. J. Phys. Oceanogr. 19, 1765-1778.

Pawlowicz, R., Farmer, D., Sotirin, B. \& Ozard, S. 1996: Shallow-water receptions from the transarctic acoustic propagation experiment. J. Acoust. Soc. Am. 100, 1482-1492.

Proshutinsky, A. Y. \& Johnson, M. A. 1997: Two circulation regimes of the wind-driven Arctic Ocean. J. Geophys. Res. 102(C6), 12,493-12,514.

Teague, W. J., Carron, M. J. \& Hogan, P. J. 1990: A comparison between the gernalized Digital Environmental Model and Levitus climatologies. J. Geophys. Res. 95(C5), 7167-7183.

Teague, W. J., Molinelli, E. J. \& Carron, M. J. 1987: A new system for management of the Master Oceanographic Observation Data Set (MOODS). Eos Trans. 68, 558-559.

Worcester, P. F., Peckham, D. A., Hardy, K. R. \& Dormer, F. O. 1985: AVATAR: second-generation transceiver electronics for ocean acoustic tomography. In: Proceedings Oceans '85: Ocean Engineering and the Environment. Pp. 654-662. San Diego, CA: IEEE. 